\title{
Mobile-Learning App to Improving Skills in the Design of Therapeutic Exercise Program: Perception, Satisfaction and Physiotherapy Student 's Demand
}

\author{
Jose-Manuel Pastora-Bernal \\ University of Granada: Universidad de Granada \\ Noelia Moreno-Morales \\ University of Malaga: Universidad de Malaga \\ María-José Estebanez-Pérez \\ University of Malaga: Universidad de Malaga \\ Guadalupe Molina-Torres \\ University of Almeria: Universidad de Almeria
}

Rocío Fernandez-Navarro

University of Granada: Universidad de Granada

Rocío Martín-Valero ( $\square$ rovalemas@uma.es)

Universidad de Malaga https://orcid.org/0000-0002-1664-3647

\section{Research}

Keywords: Learning, physiotherapy, software, satisfaction, evaluation

Posted Date: August 3rd, 2021

DOl: https://doi.org/10.21203/rs.3.rs-757592/v1

License: (c) (i) This work is licensed under a Creative Commons Attribution 4.0 International License.

Read Full License 


\section{Abstract}

Background: E-learning tools for students in health sciences present low levels of barriers and benefits for the student and the educator. No evidence is available using e-learning tools to design therapeutic exercise program skills. Research and different uses of technology in physiotherapy students are justified. The present study aimed to evaluate perception and satisfaction with an e-learning tool in five Spanish physiotherapy Universities. To evaluate the students' perception as an innovative learning experience identifying aspects to be improved and their perception respect to traditional teaching.

Methods: A descriptive study in five health sciences faculties in Spain during the 2018-2020 academic years. The use of the tool is carried out under the supervision of physiotherapy teachers in diverse disciplines.

Results: Results confirm that an e-learning tool to design therapeutic home exercise program is considered a satisfactory and innovative instrument that brings improvements in the learning of physiotherapy students with a high degree of satisfaction. Students declare aspect to be improved. All items have been valued positively with an average score of 3.41 in the set of 20 questions. It is considered a useful and necessary tool, compatible with traditional education.

Conclusions: Our research provides new knowledge using innovative technologies enhancing learning skills. Students strongly recommend the use of the e-learning tool along the physiotherapy academic period.

\section{Introduction}

The use of mobile apps in health care is growing [1]. Current and future practitioners must be equipped with the skills to utilize apps in patient care, yet few strategies exist for training health care professional students on the usage of apps [1]. The Global Observatory for eHealth defined mHealth or mobile health as medical and public health practice supported by mobile devices, such as mobile phones, patient monitoring devices, personal digital assistants, and other wireless devices [2].

The customary use of smartphones and tablets by health science students has enabled mobile learning (m-learning) to become an important component of education [3]. Therefore online technologies have become an indispensable part of the lives of students and academics in higher education, influencing learning strategies [4]. Health sciences faculty strive to stimulate learning and actively engage students in the classroom. The promotion of student work, the increase of attention, the improvement of the interaction between teachers and students, and the creation of a more relaxed atmosphere in class are some of the reasons that are driving the use of technologies in the educational field [4]. The rapid evolution of web-based information platforms, social media, and mobile apps has made the internet the primary source of information for many health professions students [5]. Today, apps, computer-assisted instruction, web-based education simulation and virtual reality are some of the technologies frequently used to support graduate education, among others [6]. 
The popularity of this type of interactive technologies is progressively increasing in the teaching-learning process of higher education. Scientific research publications confirm that generates a considerable increase in student learning, both for teaching with large groups and in small groups [7]. Researches on technological tools in health sciences students have been published including different fields [4, 7-12]. Most education apps have specific functions or aims, such as providing resources for reference while learning or in practice, learning activities and games, or organizing activities related to learning. Apps can be found by keyword search in the app stores (Google Play Store, iOS App Store), through determined categories [13].

The use of online technologies as teaching tools has shown mixed results (benefits or no difference to traditional) in health professionals' education [14]. A systematic review of the use of training tools in physiotherapy students collected the varieties of technologies used, concluding that this technology presents low levels of barriers to its use and a high number of benefits for the student and the educator [14]. Given the variety of tools and outcomes it is clear that there is a wide range of opportunities to explore. Research and different uses of mobile technology in the education of physiotherapy students are justified [15-18].

One of the most widely used physiotherapy clinical skills is the design of therapeutic exercise programmes; a regimen of physical activities designed with specific therapeutic objectives [19]. Its purposes include restoring normal musculoskeletal function, reduce pain, prevent and reduce the risk of injury, disability and its sequelae [19]. Prescribing exercise as part of a structured, safe, and effective program that includes aerobic, resistance, flexibility, and neuromotor training is essential to improving and maintain physical condition and health [20]. The American College of Sports Medicine, recommend defining programme characteristics such as exercise types and sequences, repetitions, resistance, intensity, speed, progression rules, progressive overload, rest periods and frequency for novice, intermediate and advanced training [21].

Physiotherapists require several skills including understanding of the underlying disease process or pathology, exercise physiology, biomechanics, physical principles, evidence base supporting the area as well as an awareness of psychological and safety issues. Physiotherapist must also be able to identify appropriate treatment goals in conjunction with the patient [22]. Previous research with e-learning, confirm that online technologies have many benefits to offer for physiotherapy teaching and learning including enhancing practical skills performance and knowledge acquisition, providing students with entertaining, easy accessible resources, enhancing deep learning and encouraging reflection [14].

However, no evidence is available for designing therapeutic exercise programme skills, theoretical and practical, using m-learning apps. To our knowledge, this is the first study to explore the potential for $\mathrm{m}$ learning in clinical skills acquisition in physiotherapy student's in this field.

The main objective of this study was to evaluate the potential for m-learning in clinical skills acquisition using a specific exercise prescription app. As secondary objective to evaluate student's perception and areas for improvement regarding the learning experience. 


\section{Methods}

Study Design and Recruitment

A descriptive study in 5 physiotherapy health sciences faculties in Spanish Universities was performed. A total of 67 physiotherapy students enrolled in second and third years, degree of Physiotherapy at the Universities of Malaga, University of Cadiz, University of Osuna, University of Castilla La Mancha and Catholic University of Valencia accessed freely and voluntarily to complete the questionnaire after 1 years focused m-learning experience use of the app. Participants were recruited through personalized email to inform about the survey, how to access and complete it. In addition, there is a professor who coordinates the implementation of the software in each university who inform the class on how to access the questionnaire.

\section{Description of m-Learning Experience}

In this study we use the Physiotec exercise prescription app (Fig. 1), with a free license for the use of the students during their university period. This app has been used as an intervention tool in recent research (17-19), it allows the student to create and simulate patients, create personalized programmes according to particular clinical case. The app offers a video library with more than 7000 exercises grouped by thematic modules. The use of the Physiotec app was carried out under the supervision and guidance of physiotherapy teachers in theoretical and practical sessions during the period 2018-2021. During this mlearning experience, students are engaged with didactic, workshop, and project-based experiences focused on finding, evaluating, and using the Physiotec exercise prescription app in patient care. This app educational experience was integrated into different subjects. An example of its use in the classroom is shown in Fig. 2.

\section{Evaluation of m-Learning Experience}

Students completed an ad hoc questionnaire in online format during the 2018-2020 academic year. Students were informed about the importance and objectives of the questionnaire. Participation was voluntary, anonymous and confidential. Students were informed by their teachers that their voluntary participation in the questionnaire implied their acceptance and consent to the research. The authorization of the ethics committee is not required following Law 8/2020 of January 30th, which regulates the organs of health care ethics and biomedical research in Andalusia (Spain) [23].

Furthermore, students were informed of the importance of responding sincerely to the issues raised. Participants must to be enrolled in any of the universities involved in the research and have active their free license for academic use of the Physiotec app.

\section{Questionnaire Design}

The initial questionnaire items were derived from earlier published instruments and modified to suit the context of technology in the education of physiotherapists [24-28]. Our aim was to include a 
comprehensive and representative set of measures that would allow for the validity and comprehensibility of the questionnaire. For this purpose, the elaboration of an ad hoc structured questionnaire related to satisfaction, learning and innovation, perception and interpretation outcomes with a total of 20 items was used. The questionnaire was structured in four sections as shown in Table 1. Questionnaire is available as additional file (Annex I)

Table 1

Ad hoc Questionnaire section structure

\section{Demographic Questions}

Evaluation of Satisfaction, Impact, Usability, Functionality, Design and Accessibility for the use of new technologies as educational innovation

\section{Gender - University enrolled}

Questions 1-6

Likert scale where 1 is the minimum value (Absent/None) and 4 is the maximum value (High / Very Satisfied)

Evaluation of the learning experience and its innovative methodology

Questions 7-16

Likert scale where 1 is the minimum value (Absent/None) and 4 is the maximum value (High / Very Satisfied)

Open Questions (Interpretative)

Questions 17-18

(Open-ended interpretative answers)

Direct question (Software recommendation)
Questions 19-20

(Dichotomy Questions Yes / No)

The first component of the questionnaire (Questions 1-6) was designed to evaluate satisfaction, impact, usability, functionality, design and accessibility in the use of new technologies as an educational innovation. These questions have been adapted from previous questionnaires [29-32].

The second component of the questionnaire (Questions 7-16) was designed to evaluate the learning experience and its innovative methodology through 10 items adapted from the educational innovation area of Fundación Telefónica [33].

A third part of the questionnaire included two open-ended questions for students: Question $\mathrm{N}^{\circ} 17$ to highlight any aspect of improving the application from an educational point of view. Question $N^{\circ} 18$ to express their perception on the use of this tool compared to traditional education in the creation of therapeutic exercise program.

Two final questions regarding the recommendation to other universities and its use throughout the period of physiotherapy study were included. Questions 19 and 20 of the Questionnaire.

SPSS statistic 22 was used for the management and statistical analysis of the data. Maximum and minimum values, mean score and standard deviation were determined for each item. Frequency and 
percentage analyses were carried out, presenting the information in tables and descriptive statistical graphs.

\section{Results}

Quantitative approach

A high degree of satisfaction with the m-learning app to design exercise programme was shown. All items have been valued positively with an average score of 3.41 in the set of 20 questions. None of the questions presented mean values lower than 3 on the Likert scale. No negative answered was reported by the students. Characteristics of participants is shown in Table 2.

Table 2

Characteristics of participants.

\begin{tabular}{|llll|}
\hline $\mathbf{( n = 6 7 )}$ & & Frequency & Percentage \\
\hline & Gender: Female & 37 & 55,2 \\
\hline University & UCA (Cádiz) & 13 & 19,4 \\
\hline UCV (Catholic Valencia) & 10 & 19 & 28,4 \\
\hline & UMA (Málaga) & 14,9 & \\
\hline & University of Osuna & 11 & 16,4 \\
\hline
\end{tabular}

The question with the highest average score of 3,687 was specifically aimed at the student identifying his general assessment of the m-learning tool as an educational innovation for physiotherapy students (Question $N^{\circ} 1$ ). Results of the first construct of the questionnaire (Satisfaction, Impact, Usability, Functionality, Design and Accessibility) (Questions 1-6) is show in Table 3. Results of the second construct of the questionnaire (Evaluation of the learning experience and its innovative methodology) (Questions 7-16) is show in Table 4. 
Table 3

Descriptive Statistics Questions 1-6.

\begin{tabular}{|llllll|}
\hline & N & Minimum & Maximum & Mean & Standard deviation \\
\hline Question 1 & 67 & 2,0 & 4,0 & 3,687 &, 4988 \\
\hline Question 2 & 67 & 3,0 & 4,0 & 3,597 &, 4942 \\
\hline Question 3 & 67 & 2,0 & 4,0 & 3,552 &, 6101 \\
\hline Question 4 & 67 & 2,0 & 4,0 & 3,328 &, 7047 \\
\hline Question 5 & 67 & 1,0 & 4,0 & 3,373 &, 7555 \\
\hline Question 6 & 67 & 2,0 & 4,0 & 3,493 &, 6366 \\
\hline
\end{tabular}

Table 4

Descriptive Statistics Questions 7-16

\begin{tabular}{|llllll|}
\hline & N & Minimum & Maximum & Medium & Standard deviation \\
\hline Question 7 & 67 & 2,0 & 4,0 & 3,403 &, 6527 \\
\hline Question 8 & 67 & 2,0 & 4,0 & 3,343 &, 6408 \\
\hline Question 9 & 67 & 1,0 & 4,0 & 3,358 &, 6898 \\
\hline Question 10 & 67 & 1,0 & 4,0 & 3,269 &, 7703 \\
\hline Question 11 & 67 & 2,0 & 4,0 & 3,507 &, 5607 \\
\hline Question 12 & 67 & 1,0 & 4,0 & 3,313 &, 6562 \\
\hline Question 13 & 67 & 1,0 & 4,0 & 3,269 &, 8087 \\
\hline Question 14 & 67 & 1,0 & 4,0 & 3,328 &, 7860 \\
\hline Question 15 & 67 & 2,0 & 4,0 & 3,448 &, 5582 \\
\hline Question 16 & 67 & 1,0 & 4,0 & 3,343 &, 7082 \\
\hline
\end{tabular}

Qualitative approach

Qualitative approach shown heterogeneity in the aspects to be improved like usability, previous pathologies knowledge, design and teacher support.

Results of the open-ended question (Question $N^{\circ} 17$ ) with a qualitative approach show many of the aspects that students report to be improved; a total of 27 comments (40\%) was obtained. Students' answers are listed and grouped in the following categories:

- Improve its use through mobile device 


\section{A better mobile app}

\section{Mobile application must work properly}

- Improve prior knowledge of pathologies, the function of therapeutic exercises and the design of exercise programmes.

- As a student, the use of the application is done with faculty work or any doubt you have had in particular, but until we have specific areas to apply we will not give it a higher use.

- Exercise programmes already developed depending on the pathology (Protocol)

- A better previous description of the different techniques is needed so the student could better understand the function to be achieved with each exercise. Real images and videos would make it easier to understand.

\section{Wider treatment field in pathologies}

\section{The way to do exercise programs}

\section{Improved exercise descriptions}

\section{Improve the explanations of some exercises}

- Veracity of some exercises and use from mobile.

- For my part it is a great application, the only thing that would improve is that putting a specific injury you get the exercises that benefit him, because as a student I still do not have the knowledge to know what type of exercise would be best for each pathology and sometimes I do not know what to put so that I get the specific exercises to improve the injury.

- Improve teacher support

\section{The mobile application for Android does not allow the use of the platform. I have}

to access through the computer to search for the exercises and create my programs.

- To develop an app, since from the web, it is something complicated to move, and always it is necessary to resort to the laptop or computer.

\section{Increased teacher support in the use of applications and programs such as this one}

- Improve usability and design 


\section{More simplicity}

\section{Make the application more intuitive o App Organization}

\section{How to use}

\section{Visual environment of the application}

- Faster access to the exercises I had difficulty in performing the patient's program because it is not very intuitive how to do it

Regarding the open-ended (Question No. 18) a total of 26 comments (39\%) was obtained. That question seeks to identify the student's perception of traditional teaching compared with the e-learning tool.

Students' answers are listed and grouped in two categories:

Answers that consider m-learning advantageous over traditional education

- With the software you can adjust more to specific problems that we want to solve and with traditional teaching, you see certain general cases.

\section{Is more self-taught}

\section{The use of this type of resources gives a more open vision of physiotherapy}

- Much more dynamic, educational and fast, plus the convenience of not being physical and having to carry so much paperwork.

Offers more possibilities

- The use of this application allows us to go deeper into the treatments of different pathologies rather than traditional teaching, which is adjusted to a programme that must be carried out in a specific period of time.

\section{You apply knowledge better than just seeing theory}

- With this technology it is easier to access any doubt that arises.

\section{More visual and intuitive}

\section{More useful}

\section{Cases that you find in real life}




\section{Innovations always make the experience generally more entertaining}

- It seems to me that it is much more didactic and it is very good because you can see a great variety of exercises, which give you great ideas.

\section{Much more useful and focused on real life practice}

\section{Offers an up-to-date and useful resource in professional practice}

Answers that do not consider software to be advantageous over traditional education

\section{The teaching is irreplaceable}

- Both are the perfect complement. Traditional teaching provides a more theoretical learning but it is necessary to know the basics of the field of physiotherapy. Complementing these classes with applications such as this will achieve greater involvement and learning of students.

- It is something complementary that helps you understand that what you are taught traditionally as well as giving you new ideas.

Regarding Question $N^{\circ} 19$ about the recommendation of the application for use in other physiotherapy universities, $100 \%$ of the students answered affirmative.

Regarding Question $N^{\circ} 20$ about the recommendation of its use throughout the training period of the physiotherapy degree studies, $97 \%$ of the students answered positively.

\section{Discussion}

This study examined the potential for m-learning in clinical skills acquisition using a specific exercise prescription app and evaluate student's perception. Results show a high degree of satisfaction with the specific app and aspects that students consider should be improved.

This educational m-learning app intervention is the first interactive method to educate physiotherapy students in designing therapeutic exercise program skills. The usefulness of e-learning to develop clinical competencies and specific physiotherapy skills was previously reported [5, 6, 34-38], however to our knowledge this study is the first to explore users' perceptions and satisfaction focused in designing therapeutic home exercise program skills.

Current literature reveals that healthcare trainees in a variety of practice environments share similar trends and perceptions of health care apps. Our findings were similar to those obtained by other elearning experiences assessing students experiences and perceptions [37, 39, 40]. 
In the present study the app was used as a supplement to on campus education to enhance the knowledge and training of students. Students used the tool in the resolution of clinical cases, individual and group tasks in various contents such as musculoskeletal and neurological pathologies, injury prevention and risk of falls. This flexibility to be used in different fields of physiotherapy can be considered an important advantage over applications focused on a single field of action.

Positive responses about the m-learning experience and positive responses about innovative methodology confirm that students are interested in using customary technologies. In this context, the change of attitude of the students is becoming more and more evident. They participate, become involved and show great affinity especially when they use known technologies that they encounter on a daily basis [41] what could be considered an important advantage compared to face-to-face master classes. Nevertheless, students continue to point out that these learning tools should be a complement to classroom training, which they consider irreplaceable. This is a clear disadvantage of mobile learning. Some experts have pointed out, software and hardware issues, distraction and misuse as frequent disadvantages of mobile learning while variety of content and access from anywhere in the world and anytime are recognized as the main advantages $[42,43]$.

Positive results of the first construct of the questionnaire, especially questions about impact and usability, allows us to hypothesize on the adoption of educational strategies to facilitate self-learning in designing therapeutic exercise programmes may expand the implementation of this assessment approach in routine clinical practice.

E-learning has an evident potential to increase re-training for students and professionals promoting selflearning strategies [44]. Students who responded to the open-ended questions insisted on the need to expand their use to mobile technologies (laptops, cell phones, tablets, etc.), a question that had been suggested in previous research in higher education as it can help revive constructivist learning [45]. In student's opinion, m-learning cannot replace on-campus learning of physiotherapy student's skills but it appears to be valuable as an additional or complementary activity as expressed by students during the survey.

Within app stores, star ratings and reviews are the main indicators of app quality or value; however, these can be subjective and only relevant if the reviewer has needs and expectations similar to the potential app user. In this context there is evolving literature aiming to identify apps for health conditions, to support self-management, education, or behavior change and to evaluate app quality [46]. For instance, a rubric for evaluating educational apps emphasizes the teaching and learning component of an app; a balance between general and specific criteria is needed to ensure that the rubric is both reliable and objective [47].

Satisfaction with m-learning in university students has been evaluated with multiple instruments [48]; online questionnaires and surveys was a widely used tool [49]. The specifications of the m-learning tools, the student profiles and the outcomes to be measured, make the validity, reliability and objectivity of 
these evaluations difficult. In our research the use of an ad hoc questionnaire intends to approach the specifications of the m-learning tool and the particularities of the Spanish physiotherapy students.

The most commonly investigated technologies in physiotherapy e-learning tools were websites and discussion boards as has been shown in previous systematic reviews [14]. Websites show improvement in theoretical and practical skills and confirm that student need less time to perform a task [14, 36, 37].

Of special interest is the development of qualitative research with focus groups that include both students and faculty and that allow the achievement of solid constructs, issues that are on the immediate agenda of the authors of this study. In this research we present each of the answers offered by the students in their own words. Although we have grouped the answers into categories, pointing out their own words allows a better qualitative interpretation.

Most of students consider the use of this m-learning tool advantageous from traditional education and conclude with unanimous agreement to recommend the use in universities along the physiotherapy academic period. The students expressed openness and sincerity in their positive and negative responses and continue working with this educational tool in the current academic year.

An additional factor that is relevant for health-related mobile apps is the credibility of the app content. In the education setting, when learning clinical skills, it is critical to learn skills that are relevant and accurate in the local health care environment. Apps that focus on clinical skills provide opportunities for just-intime learning in clinical settings where textbooks are not available [50,51].

While promising, there are a number of limitations of the current study that need to be addressed in future research including the limited sample size and lack of a true control group. Another limitation is the frame of reference, that is, that the measurement properties of the questionnaire are only evaluated when applied to one unique app and in one context.

\section{Conclusion}

This research provides new knowledge in the perception and satisfaction using a specific m-learning apps. Study results respond to the objectives set, reporting a high degree of general satisfaction and presenting a homogeneous level of positive valuation in the set of questionnaire items.

These results confirm that an m-learning app to design therapeutic exercise program is considered a satisfactory and innovative instrument that brings improvements in the learning of physiotherapy students.

Future physiotherapists will likely be the generation to formally adopt mobile technology into their workflow and clinical practice. This research confirm that m-learning experience focus in the design of therapeutic program skills with the Physiotec app, is an educational innovation for physiotherapy students and is considered a didactic tool recommended for use throughout the education period. 
Research with larger sample size, qualitative research including students and faculty, questionnaire validation research, and clinical trials comparing the tool with campus education must bring greater strength to the statements provided by this study.

Students strongly recommend the use of the m-learning app along the physiotherapy academic period.

Practice Points

\section{Declarations}

\section{Ethics and consent to participate}

Participation was voluntary, anonymous and confidential. Students were informed verbally by their teachers that their voluntary participation in the questionnaire implied their acceptance and consent to the research. The authorization of the ethics committee is not required following Law 8/2020 of January 30th, which regulates the organs of health care ethics and biomedical research in Andalusia (Spain).

\section{Consent for publication}

Not Applicable

\section{Author's Contributions}

All authors have made significant contributions to the article. J.-M.P.-B., M.J.E.P, N.M.M and R.M.-V. coordinated the project, contributed to the conception and design of this study and drafted the manuscript. G.M-T were responsible for methodological guidance. R.F-N contributed to coordinating data acquisition and analysis, and spelling review. All authors have read and agreed to the published version of the manuscript.

\section{Funding}

No funding was obtained for this study

\section{Acknowledgements}

This study was possible thanks to the free license for academic use provided by Physiotec $\circledast$.

\section{Competing Interests}


There are no potential conflicts of interest or any financial or personal relationships with other people or organizations that could inappropriately bias the conduct and findings of this study.

\section{Availability of data and materials}

The datasets used and/or analyzed during the current study available from the corresponding author on reasonable request.

\section{Additional files}

Supplementary Material (Annex I Ad Hoc Questionnaire English version))

\section{References}

1. Suner A, Yilmaz Y, Pişkin B. Mobile learning in dentistry: Usage habits, attitudes and perceptions of undergraduate students. PeerJ PeerJ Inc; 2019;2019(7). [doi: 10.7717/peerj.7391].

2. WHO Global Observatory for eHealth. (2011). mHealth: new horizons for health through mobile technologies: second global survey on eHealth. World Health Organization. https://apps.who.int/iris/handle/10665/44607. 2011.

3. Payne KFB, Wharrad $\mathrm{H}$, Watts K. Smartphone and medical related App use among medical students and junior doctors in the United Kingdom (UK): A regional survey. BMC Med Inform Decis Mak BioMed Central Ltd; 2012 Dec 30;12(1):121. PMID:23110712.

4. Cheryl Moredich EM. Engaging Students Through the Use of Classroom Response Systems. Nurse Educ Nurse Educator; 2007 May 1;32(3):113-116. [doi: 10.1097/01.nne.0000270225.76661.74].

5. Carolyn Giordano CG. Health professions students' use of social media - PubMed [Internet]. [cited 2020 Nov 10]. Available from: https://pubmed.ncbi.nlm.nih.gov/21695367/.

6. Jwayyed S, Kirk A, Stiffler, Wilber ST, Southern A, Weigand J, Bare R, Gerson LW. Technology-assisted education in graduate medical education: A review of the literature. Int J Emerg Med Int J Emerg Med. 2011. [doi: 10.1186/1865-1380-4-51].

7. Caldwell JE. Clickers in the Large Classroom: Current Research and Best-Practice Tips. CBE-Life Sci Educ 2007 Mar;6(1):9-20. [doi: 10.1187/cbe.06-12-0205].

8. Alexander CJ, Crescini WM, Juskewitch JE, Lachman N, Pawlina W. Assessing the integration of audience response system technology in teaching of anatomical sciences. Anat Sci Educ John Wiley \& Sons, Ltd; 2009 Jul 1;2(4):pp. 160-6. [doi: 10.1002/ase.99].

9. Efstathiou N, Bailey C. Promoting active learning using Audience Response System in large bioscience classes. Nurse Educ Today Churchill Livingstone; 2012 Jan 1;32(1):91-95. [doi: 10.1016/J.NEDT.2011.01.017]. 
10. DeBourgh GA. Use of classroom "clickers" to promote acquisition of advanced reasoning skills. Nurse Educ Pract Churchill Livingstone; 2008 Mar 1;8(2):76-87. [doi: 10.1016/J.NEPR.2007.02.002].

11. Uhari $M$, Renko $M$, Soini $H$. Experiences of using an interactive audience response system in lectures. BMC Med Educ BioMed Central. 2003 Dec;17(1):12. [doi: 10.1186/1472-6920-3-12]. 3 ) .

12. Sandars J, Morrison C. What is the Net Generation? The challenge for future medical education. Med Teach 2007 Mar 3;29(2-3):85-8. PMID:17701615.

13. Aungst TD, Clauson KA, Misra S, Lewis TL, Husain I. How to identify, assess and utilise mobile medical applications in clinical practice. Int J Clin Pract Int J Clin Pract. 2014 Feb;68(2):155-62. PMID:24460614.

14. Mącznik AK, Ribeiro DC, Baxter GD. Online technology use in physiotherapy teaching and learning: a systematic review of effectiveness and users' perceptions. BMC Med Educ 2015 Dec 28;15(1):160. PMID:26415677.

15. Olivier B, Verdonck M, Caseleijn D. Digital technologies in undergraduate and postgraduate education in occupational therapy and physiotherapy: a scoping review. JBI Evid Synth Lippincott Williams Wilkins. 2020 May;18(5):863-92. [doi: 10.11124/JBISRIR-D-19-00210].

16. Patton N, Higgs J, Smith M. Using theories of learning in workplaces to enhance physiotherapy clinical education. Physiother Theory Pract. 2013 Oct;29(7):493-503. PMID:23289960.

17. Barradell S. Moving forth: Imagining physiotherapy education differently. Physiother Theory Pract Taylor Francis Ltd. 2017 Jun;33(6)(3):439-47. PMID:28509604.

18. Tederko P, Krasuski M, Lyp M, Cabak A, Białoszewski D, Stanisławska I, Tarnacka B. Perception of the role of physical and rehabilitation medicine among physiotherapy students. J Rehabil Med Foundation for Rehabilitation Information. 2018;50(7):661-7. PMID:30003266.

19. Verhagen E, Engbers L. The physical therapist's role in physical activity promotion. Br J Sports Med 2008 Dec 3;43(2):99-101. PMID:18838405.

20. Kisner C, Colby LA. Ejercicio terapéutico: fundamentos y técnicas. Médica Panamericana; 2010. ISBN:9789500600965.

21. Slade SC, Keating JL. Exercise prescription: A case for standardised Reporting. Br J Sports Med. BMJ Publishing Group Ltd and British Association of Sport and Exercise Medicine; 2012. p. 1110-1113. PMID:22089077.

22. of Therapeutic Exercise Design. | Musculoskeletal Key [Internet]. [cited 2020 Nov 11]. Available from: https://musculoskeletalkey.com/of-therapeutic-exercise-design/.

23. Decreto $8 / 2020$, de 30 de enero, por el que se regulan los órganos de ética asistencial y de la investigación biomédica en Andalucía. [Internet]. [cited 2021 Jan 19]. Available from: https://www.juntadeandalucia.es/boja/2020/24/3.

24. Centre for Educational Research and Innovation., Organisation for Economic Co-operation and Development. Inspired by technology, driven by pedagogy: a systematic approach to technologybased school innovations. OECD; 2010. ISBN:9789264094437. 
25. Habilidades y competencias. del siglo XXI para los aprendices del nuevo milenio en los países de la OCDE. 2010.

26. Centre for Educational Research and Innovation. Leadership for 21 st century learning. ISBN: 9789264205406.

27. Modelos de protocolos para la. evaluación de actividades de I + D e innovación.

28. Hernández Ortega J, Pennesi Fruscio M, Sobrino López D, Vázquez Gutiérrez A. Tendencias emergentes en educación con TIC. Espiral; 2012. ISBN:9788461604319.

29. Almeida RS de, Bourliataux-Lajoinie S, Martins M. Satisfaction measurement instruments for healthcare service users: a systematic review. Cad Saude Publica. 2015 Jan;31(1):11-25. PMID:25715288.

30. Bakken S, Grullon-Figueroa L, Izquierdo R, Lee N-J, Morin P, Palmas W, Teresi J, Weinstock RS, Shea S, Starren J. IDEATel Consortium. Development, validation, and use of English and Spanish versions of the telemedicine satisfaction and usefulness questionnaire. J Am Med Inform Assoc. 2006;13(6):660-7. PMID:16929036.

31. Dunleavy G, Nikolaou CK, Nifakos S, Atun R, Law GCY, Tudor Car L. Mobile Digital Education for Health Professions: Systematic Review and Meta-Analysis by the Digital Health Education Collaboration. J Med Internet Res 2019 Feb 12;21(2):e12937. PMID:30747711.

32. Nicklen P, Keating JL, Maloney S. Exploring Student Preconceptions of Readiness for Remote-Online Case-Based Learning: A Case Study. JMIR Med Educ 2016 Apr 28;2(1):e5. PMID:27731854.

33. Área de Innovación. Educativa de Fundación Telefónica (Explorador de Innovación Educativa). Decálogo de un proyecto innovador: guía práctica Fundación Telefónica. 2014.

34. Arroyo-Morales M, Cantarero-Villanueva I, Fernández-Lao C, Guirao-Piñeyro M, Castro-Martín E, DíazRodríguez L. A blended learning approach to palpation and ultrasound imaging skills through supplementation of traditional classroom teaching with an e-learning package. Man Ther Man Ther. 2012 Oct;17(5):474-8. PMID:22579034.

35. Knox GM, Snodgrass SJ, Stanton TR, Kelly DH, Vicenzino B, Wand BM, Rivett DA. Physiotherapy students' perceptions and experiences of clinical prediction rules. Physiother (United Kingdom) Elsevier Ltd; 2017 Sep 1;103(3):296-303. PMID:27553643.

36. Jones AYM, Dean E, Hui-Chan C. Comparison of teaching and learning outcomes between videolinked, web-based, and classroom tutorials: An innovative international study of profession education in physical therapy. Comput Educ 2010 May;54(4):1193-1201. [doi: 10.1016/j.compedu.2009.11.005].

37. Preston E, Ada L, Dean CM, Stanton R, Waddington G, Canning C. The Physiotherapy eSkills Training Online resource improves performance of practical skills: A controlled trial. BMC Med Educ BMC Med Educ; 2012;12(1). PMID:23176318.

38. Faure $M$, Unger M. M and B. Sabinet | Physiotherapy students perceptions of an innovative approach to clinical practice orientation [Internet]. [cited 2020 Nov 10]. Available from: https://journals.co.za/content/sajp/58/2/AJA03796175_864. 
39. Gardner P, Slater H, Jordan JE, Fary RE, Chua J, Briggs AM. Physiotherapy students' perspectives of online e-learning for interdisciplinary management of chronic health conditions: A qualitative study Approaches to teaching and learning. BMC Med Educ 2016; PMID:26879982.

40. Moore WA, Smith AR. Effects of video podcasting on psychomotor and cognitive performance, attitudes and study behaviour of student physical therapists. Innov Educ Teach Int Routledge. 2012 Nov;49(4):401-14. [doi: 10.1080/14703297.2012.728876].

41. Casuso-Holgado MJ, Moreno-Morales N, Labajos-Manzanares MT, Montero-Bancalero FJ. Características psicométricas de la versión española de la escala UWES-S en estudiantes universitarios de Fisioterapia. Fisioterapia Elsevier Doyma; 2017 Jan 1;39(1):4-9. [doi: 10.1016/J.FT.2016.02.003].

42. TAYLA HOLMAN. Dignity Health I The Pros and Cons of Mobile Health Apps [Internet]. [cited 2021 May 19]. Available from: https://www.dignityhealth.org/articles/the-pros-and-cons-of-mobile-healthapps.

43. James Thomes. Mobile Learning: Advantages And Disadvantages - eLearning Industry [Internet]. [cited 2021 May 19]. Available from: https://elearningindustry.com/mobile-learning-advantagesdisadvantages.

44. Filippucci E, Meenagh G, Ciapetti A, lagnocco A, Taggart A, Grassi W. E-learning in ultrasonography: A web-based approach. Ann Rheum Dis BMJ Publishing Group. 2007 Jul;66(7):962-5.

PMID:17329310.

45. Lom TC, Van M. Impact Constructivist Learning Theory and Mobile Technology Integration - Theories of Educational Technology [Internet]. [cited 2020 Nov 12]. Available from:

https://sites.google.com/a/boisestate.edu/edtechtheories/craig_and_vanlom.

46. Gladman T, Tylee G, Gallagher S, Mair J, Rennie SC, Grainger R. A tool for rating the value of health education mobile apps to enhance student learning (MARuL): Development and usability study. JMIR mHealth uHealth JMIR Publications Inc.; 2020;8(7). PMID:32735228.

47. Lee J-S, Kim S-W. Validation of a Tool Evaluating Educational Apps for Smart Education. J Educ Comput Res Baywood Publishing Co. Inc.; 2015 Jun 26;52(3):435-450. [doi: 10.1177/0735633115571923].

48. Melo M, Contreras J, Arias J. Validación de un cuestionario de satisfacción de los alumnos, para determinar el impacto de la introducción de la gamificación con el uso de los dispositivos móviles en el aula, en el aprendizaje de estudiantes universitarios. Atas CIAIQ2017 > > Investigação Qual em Eng e Tecnol Cual en Ing y Tecnol 44.

49. González-Peiteado MP-JMPAM. La Revista Iberoamericana de Educación a Distancia (RIED). RIED Rev Iberoam Educ a Distancia. Asociación Iberoamericana de Educación Superior a Distancia; 2017.

50. Fiore P. How to evaluate mobile health applications: A scoping review. Stud Health Technol Inform IOS Press; 2017. pp. 109-14. PMID:28186025.

51. Hurst EJ. Evaluating Health and Wellness Mobile Applications. Hosp Librariansh J Routledge; 2018 Jul 3;18(3):266-278. [doi: 10.1080/15323269.2018.1472928]. 

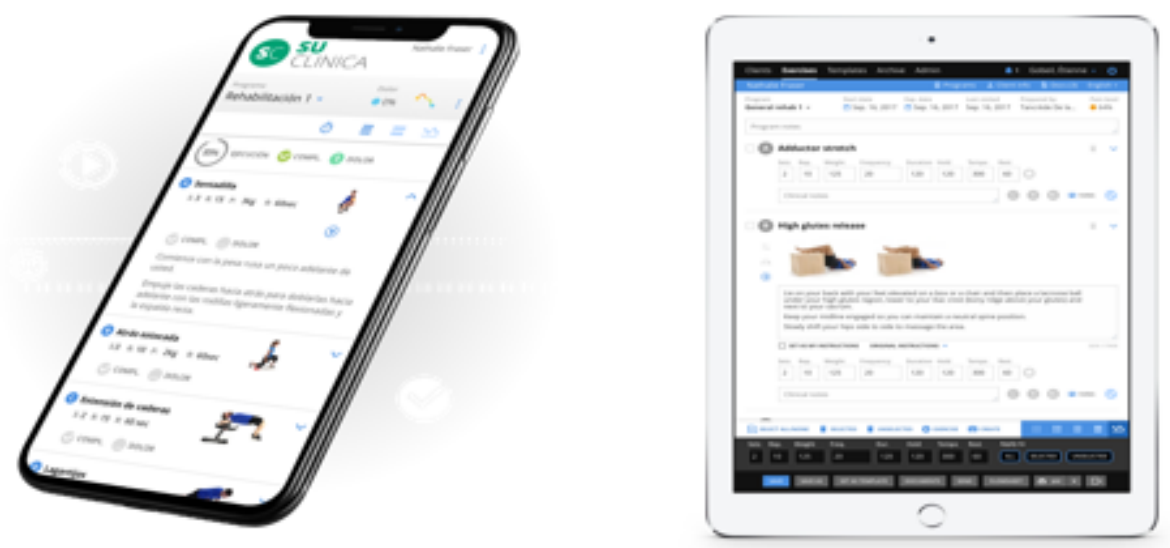

Figure 1

\section{Physiotec app}
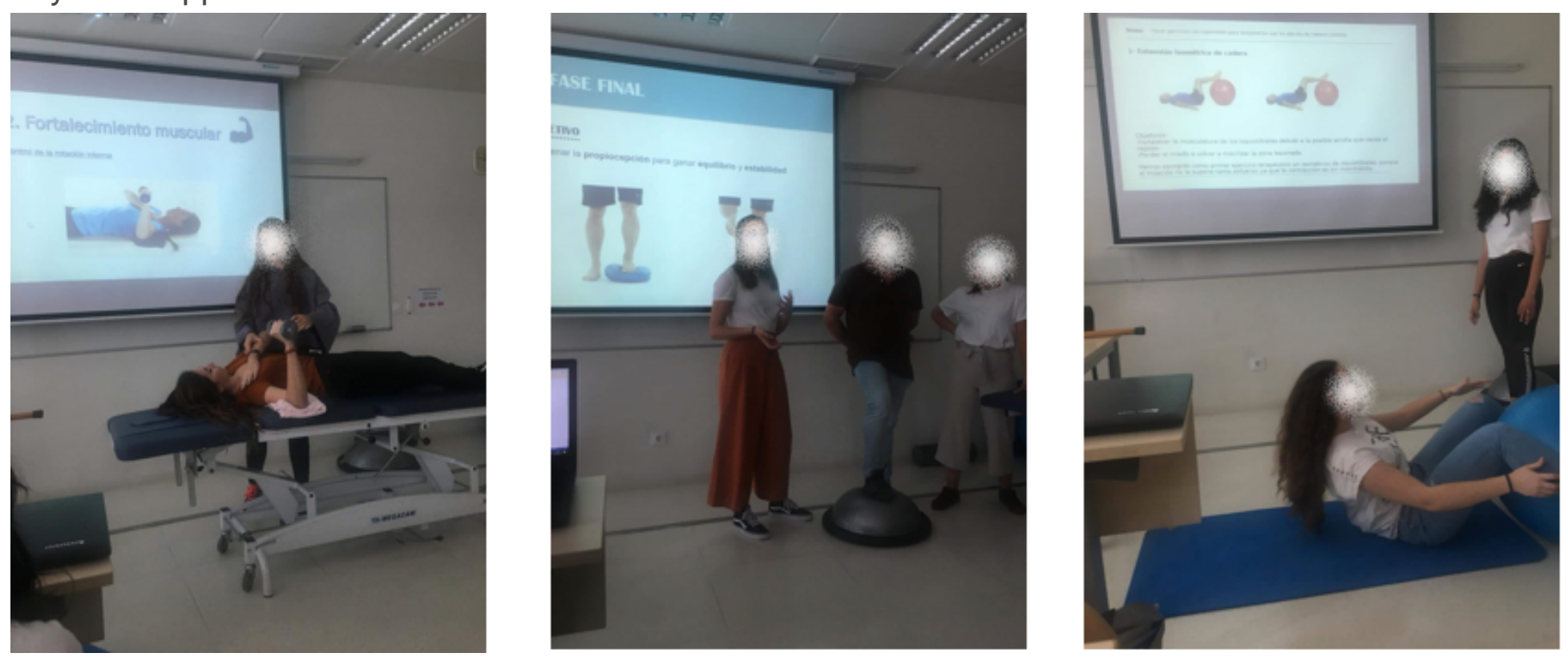

Figure 2

Student's skills acquisition using an exercise prescription app

\section{Supplementary Files}

This is a list of supplementary files associated with this preprint. Click to download.

- AppendixA.AdHocQuestionnaireEnglishversion25.06.21.pdf 